\title{
Synthesis and structure of water-soluble Sb quantum dots and enhanced corrosion inhibition performance and mechanisms
}

\author{
Renhui Zhanga, , Liping Xionga,b*, Zhongyi He ${ }^{\mathrm{a}, \mathrm{b}^{*}}$, Jibin $\mathrm{Pu}^{\mathrm{c}}$, Lei Guo ${ }^{\mathrm{d}}$ \\ ${ }^{a}$ Key Materials Engineering Research Center of Rail Transit in Jiangxi Province, \\ Nanchang 330013, People's Republic of China \\ ${ }^{\mathrm{b} S c h o o l}$ of Materials Science and Engineering, East China JiaoTong University, \\ Nanchang 330013, People's Republic of China \\ ${ }^{`}$ Key Laboratory of Marine Materials and Related Technologies, Zhejiang Key \\ Laboratory of Marine Materials and Protective Technologies, Ningbo Institute of \\ Materials Technology and Engineering, Chinese Academy of Sciences, Ningbo \\ 315201, People's Republic of China \\ ${ }^{\mathrm{d}}$ Research Center of Material and Chemical Engineering, School of Material and \\ Chemical Engineering, Tongren University, Tongren, 554300, People's Republic of \\ China \\ Corresponding to author: 3067@ecjtu.edu.cn, zhyhe@ecjtu.edu.cn
}




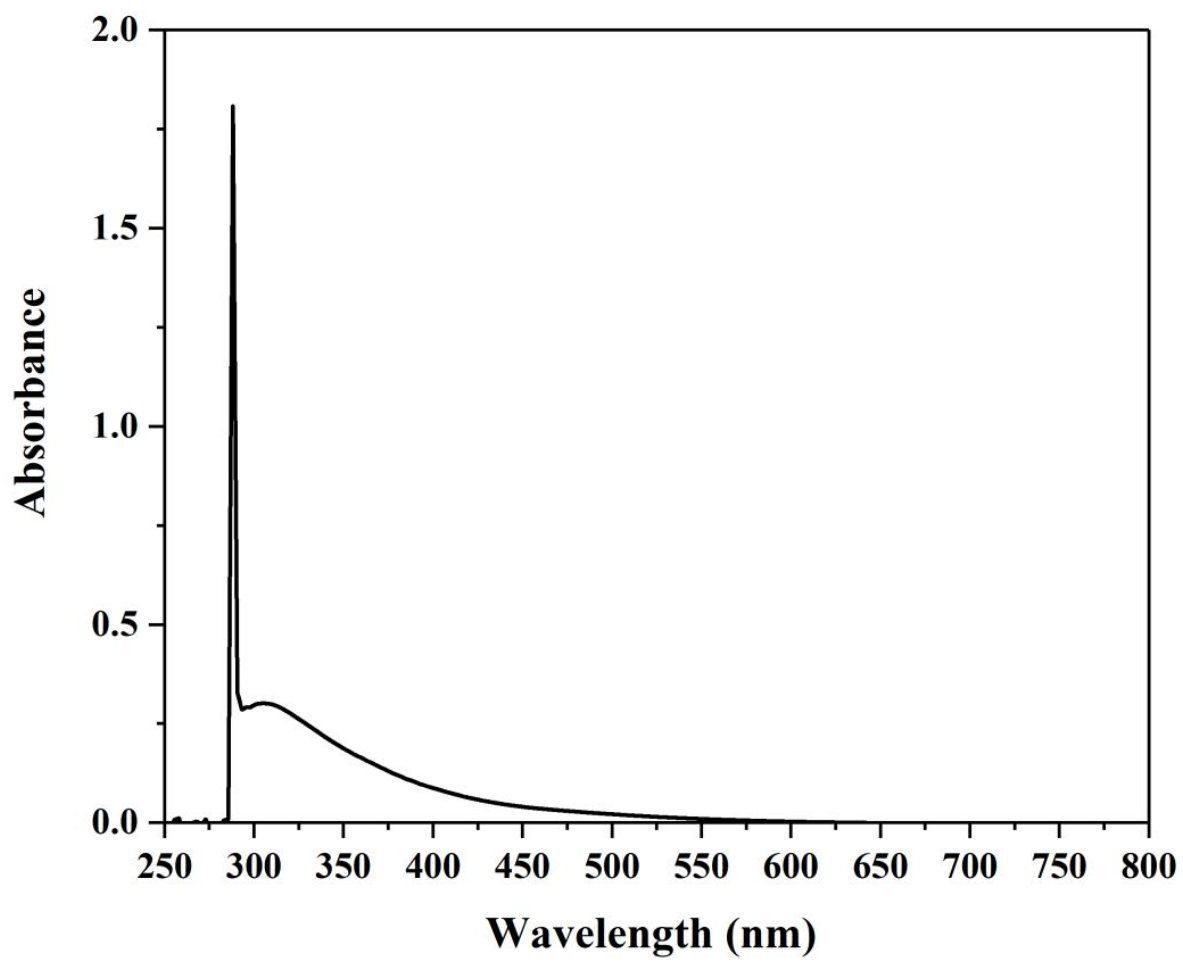

Figure S1 UV-vis spectra of SQDs.

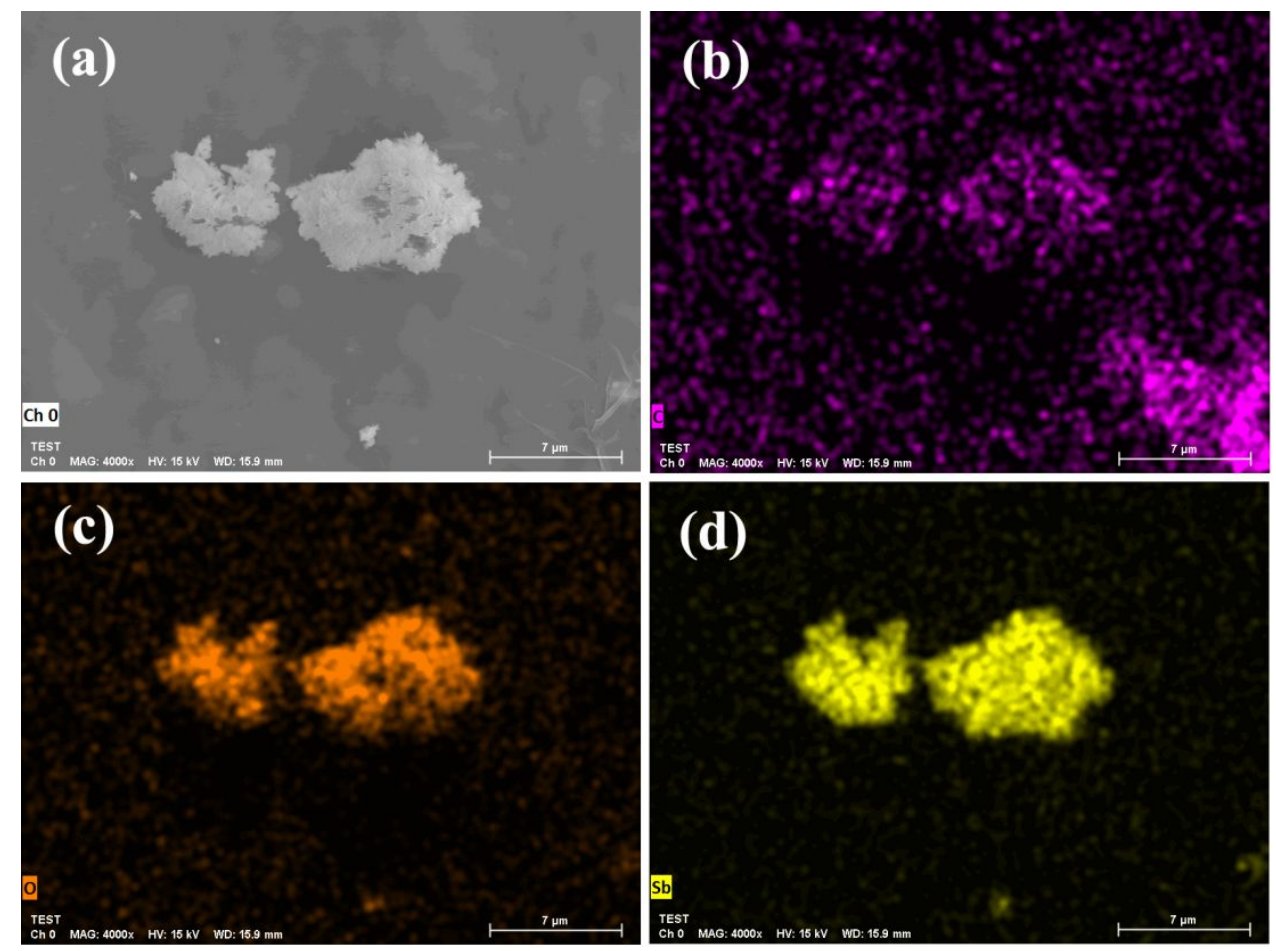

Figure S2 (a) SEM image of Sb quantum dots, and EDS mappings of (b) C, (c) O and (d) Sb element. 


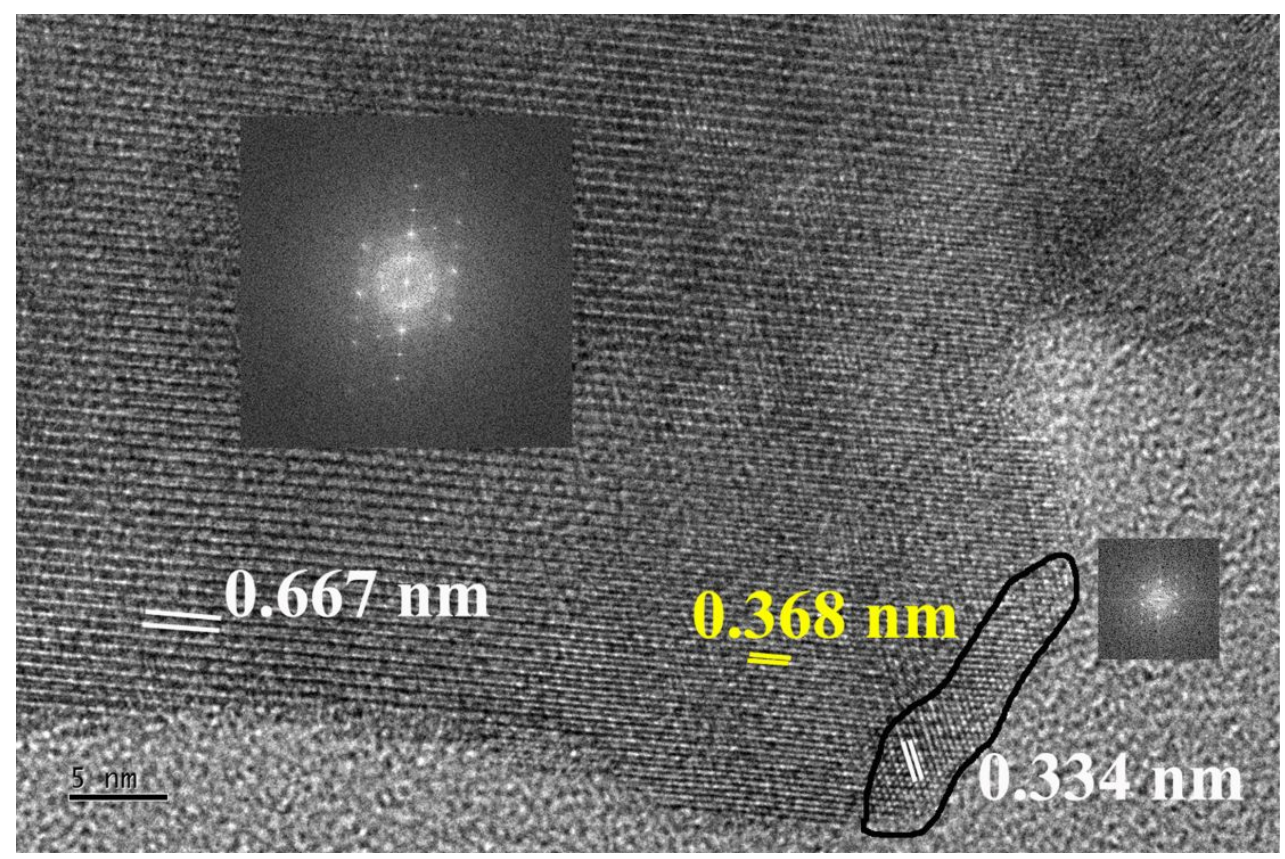

Figure S3 High resolution TEM image of Sb quantum dots.

Because the layered space of bulk $\mathrm{Sb}$ is $0.184 \mathrm{~nm}[1]$, in Figure $\mathrm{S} 3$, the layered space of 0.368 and $0.667 \mathrm{~nm}$ indicates that the layered space is enlarged during exfoliation, which is larger than 0.184 and $0.483 \mathrm{~nm}$ compared to bulk Sb. The crystals with d-space of $0.334 \mathrm{~nm}$ grown along the edge of $\mathrm{Sb}$ multilayers are detected as supported by FFT image in Figure S3, which correspond to single-crystal graphene as reported by Zhang et al[2].
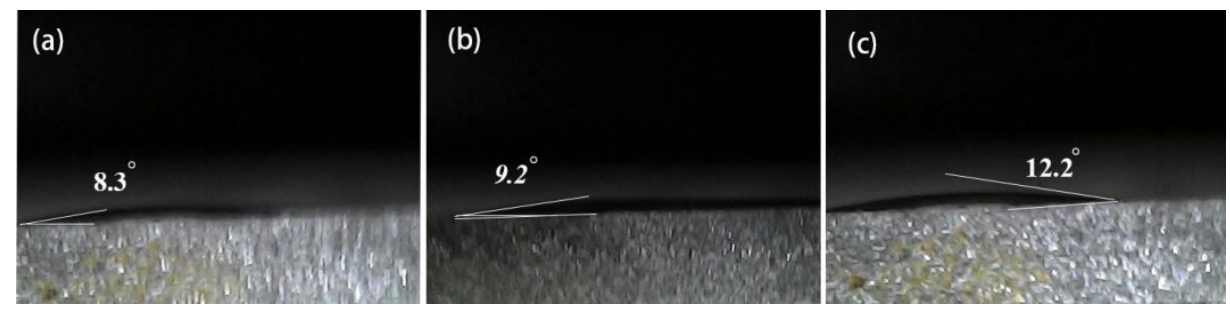

Figure S4 Water contact angle of (a) $10 \mathrm{mg} / \mathrm{L}$, (b) $50 \mathrm{mg} / \mathrm{L}$ and (c) $100 \mathrm{mg} / \mathrm{L}$.

As dropping a water droplet on Q235 steel surface, the water droplet slowly flattens on Q235 steel surface, the lower contact angles were obtained in Figure 3, the water contact angles were $8.3^{\circ}, 9.2^{\circ}$ and $12.2^{\circ}$ for the concentration of $10 \mathrm{mg} / \mathrm{L}, 50$ $\mathrm{mg} / \mathrm{L}$ and $100 \mathrm{mg} / \mathrm{L}$, respectively.

\section{References}

[1] J. Gu, Z. Du, C. Zhang, J. Ma, B. Li, S. Yang, Liquid-Phase Exfoliated Metallic Antimony

Nanosheets toward High Volumetric Sodium Storage, Advanced Energy Materials, 7 (2017)

1700447. 
[2] J. Zhang, L. Lin, K. Jia, L. Sun, H. Peng, Z. Liu, Controlled Growth of Single-Crystal Graphene Films, Adv. Mater., 2 (2019) 1903266. 